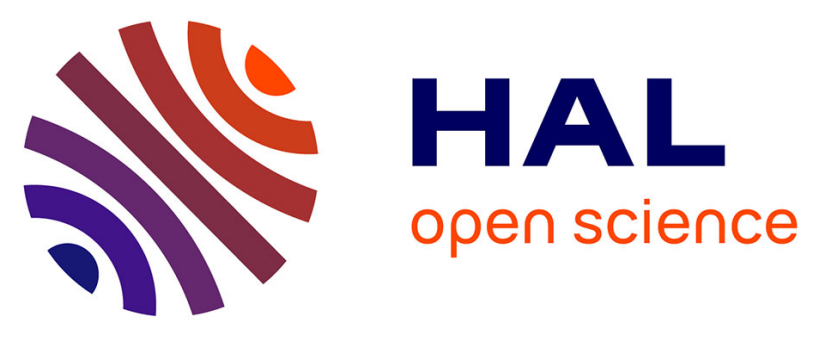

\title{
Superconducting instrumentation for high Reynolds turbulence experiments with low temperature gaseous helium
}

Sylvain S. Pietropinto, Cédric Poulain, Christophe Baudet, Bernard Castaing, Benoît Chabaud, Yves Gagne, Bernard Hébral, Yves Ladam, Philippe Lebrun, Olivier Pirotte, et al.

\section{To cite this version:}

Sylvain S. Pietropinto, Cédric Poulain, Christophe Baudet, Bernard Castaing, Benoît Chabaud, et al.. Superconducting instrumentation for high Reynolds turbulence experiments with low temperature gaseous helium. Physica C: Superconductivity and its Applications, 2003, 386, pp.512-516. 10.1016/S0921-4534(02)02115-9 . hal-00183626

\section{HAL Id: hal-00183626 https://hal.science/hal-00183626}

Submitted on 28 Jan 2020

HAL is a multi-disciplinary open access archive for the deposit and dissemination of scientific research documents, whether they are published or not. The documents may come from teaching and research institutions in France or abroad, or from public or private research centers.
L'archive ouverte pluridisciplinaire HAL, est destinée au dépôt et à la diffusion de documents scientifiques de niveau recherche, publiés ou non, émanant des établissements d'enseignement et de recherche français ou étrangers, des laboratoires publics ou privés. 


\title{
Superconducting instrumentation for high Reynolds turbulence experiments with low temperature gaseous helium
}

\author{
S. Pietropinto ${ }^{\text {a }}$, C. Poulain ${ }^{\mathrm{b}}$, C. Baudet ${ }^{\mathrm{b}}$, B. Castaing ${ }^{\mathrm{c}}$, B. Chabaud ${ }^{\mathrm{a}}$, \\ Y. Gagne ${ }^{\mathrm{b}}$, B. Hébral ${ }^{\mathrm{a}, \mathrm{d}, *}, \mathrm{Y}$. Ladam ${ }^{\mathrm{c}}$, P. Lebrun ${ }^{\mathrm{e}}$, O. Pirotte ${ }^{\mathrm{e}}$, P. Roche $^{\mathrm{a}}$ \\ ${ }^{\text {a } C R T B T ~ C N R S-U J F-I N P G, B P}$ 166, 38042 Grenoble Cedex 9, France \\ ${ }^{\mathrm{b}}$ LEGI UJF-INPG-CNRS, 38041 Grenoble Cedex 9, France \\ ${ }^{\mathrm{c}}$ Department of Physics, ENSL-CNRS, 69364 Lyon Cedex 7, France \\ d CRETA CNRS-UJF-INPG, 38042 Grenoble Cedex 9, France \\ ${ }^{\mathrm{e}}$ CERN, 1211 Geneva 23, Switzerland
}

\begin{abstract}
Turbulence is of common experience and of high interest for industrial applications, despite its physical grounds is still not understood. Cryogenic gaseous helium gives access to extremely high Reynolds numbers $(R e)$. We describe an instrumentation hosted in CERN, which provides a $6 \mathrm{~kW} @ 4.5 \mathrm{~K}$ helium refrigerator directly connected to the experiment. The flow is a round jet; the flow rates range from $20 \mathrm{~g} / \mathrm{s}$ up to $260 \mathrm{~g} / \mathrm{s}$ at $4.8 \mathrm{~K}$ and about $1.2 \mathrm{bar}$, giving access to the highest controlled $R e$ flow ever developed. The experimental challenge lies in the range of scales which have to be investigated: from the smallest viscous scale $\eta$, typically $1 \mu \mathrm{m}$ at $R e=10^{7}$ to the largest $L \sim 10 \mathrm{~cm}$. The corresponding frequencies: $f=v / \eta$ can be as large as $1 \mathrm{MHz}$. The development of an original micrometric superconducting anemometer using a hot spot and its characteristics will be discussed together with its operation and the perspectives associated with superconducting anemometry.
\end{abstract}

Keywords: Turbulence-jet-instrumentation

The study of intermittency in turbulence is a long-standing question [1]. One purpose is to understand how the energy injected at a large scale, typically the size $L$ of the flow, will cascade down

\footnotetext{
* Corresponding author. Address: CRTBT CNRS-UJFINPG, BP 166, 38042 Grenoble Cedex 9, France. Fax: +33-476-87-50-60.

E-mail address: hebral@grenoble.cnrs.fr (B. Hébral).
}

to small scales $(\eta)$, where this energy is dissipated within viscosity processes. Using the value of the Reynolds number: $R e=v L / v$, where $v$ is the mean flow velocity and $v$ the fluid kinematic viscosity, one can show that: $L / \eta \approx R e^{3 / 4}$ [2]. Large $R e$ numbers are then needed in order to investigate a large range cascade process. To vary this range, experiments in a single geometry are needed.

Air is not fully appropriate as a fluid for this kind of investigations. Large $R e$ numbers can be 
reached in wind tunnels of large size (from typically 1 to $20 \mathrm{~m}$ in diameter); the $R e$ number can only be varied on a narrow range in these experiments. Geophysical experiments give also access to very high $\operatorname{Re}\left(10^{8}-10^{9}\right)$, but in uncontrolled geometry conditions.

Thus, cryogenic gaseous helium appears as an exceptional fluid. It has an extremely low viscosity: $v=8 \times 10^{-8} \mathrm{~m}^{2} / \mathrm{s}$ at $4.5 \mathrm{~K}$ (230 times lower than air at $300 \mathrm{~K}$ ) and it is easy to vary the flow rate, at constant pressure, on at least one order of magnitude. First experiments were developed at Grenoble in a laboratory cell $(\phi=10 \mathrm{~cm}, h=30 \mathrm{~cm})$ $[3,4]$, where $R e$ around $10^{6}$ was reached.

We will discuss the velocity measurement instrumentation in a new experiment hosted in CERN at Geneva where we had access to a large high size helium refrigerator facility providing 6 $\mathrm{kW}$ cooling power at $4.5 \mathrm{~K}$ and flow rates up to $R e=10^{7}$.

\section{The cryostat}

On Fig. 1 we show a sketch of the $4.6 \mathrm{~m}$ high, $1.4 \mathrm{~m}$ outer diameter cryostat. The flow develops from a $25 \mathrm{~mm}$ diameter nozzle in a $1.1 \mathrm{~m}$ diameter chamber. On a vertically moving ring, placed in the experiment $1250 \mathrm{~mm}$ downstream the nozzle, are located three superconducting anemometers, one being on the jet axis. A stabilizing grid is placed at $825 \mathrm{~mm}$ down the anemometers: this grid breaks the large turbulent structure, which might randomly attach the jet to the chamber walls [5].

\section{The flowmeter}

The flow rate measurement is achieved with an original flowmeter using a constantan-NbTi superconductor thermocouple with 58 junctions. At about $14 \mathrm{~cm}$ from the top of the $25 \mathrm{~cm}$ long flowmeter $(\phi=5 \mathrm{~cm})$ a $\phi=0.5 \mathrm{~mm}$ constantan wire heater is placed as a grid of $3 \mathrm{~mm}$ mesh: this allows a homogenous heating of the incoming helium flow. Twenty-nine thermocouple junctions are $115 \mathrm{~mm}$ upstream the heater and 29 are $75 \mathrm{~mm}$ downstream. To minimize the thermal conducti-

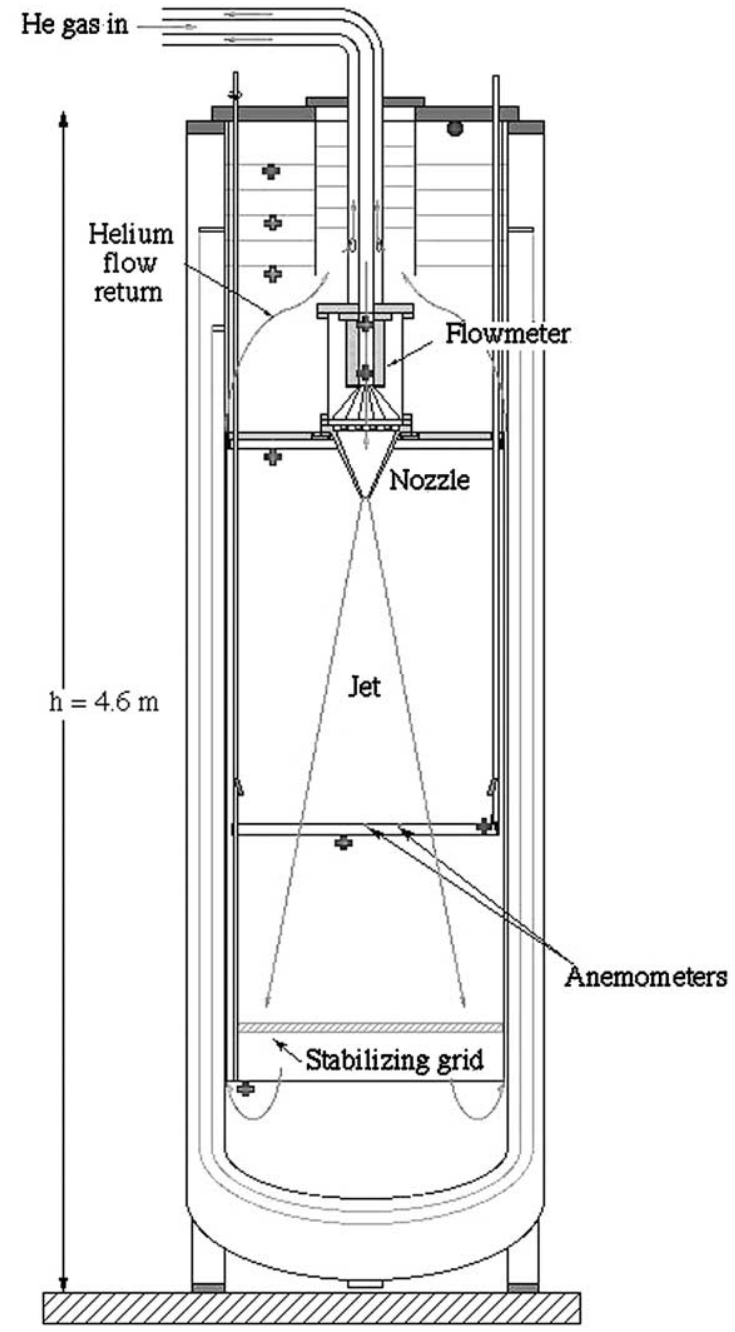

Fig. 1. Sketch of the jet experiment at CERN. The represent thermometers.

vity along the flowmeter walls, we use double stainless steel walls vacuum insulated, the inner one being $1 \mathrm{~mm}$ thick.

In order to precisely measure the thermocouple voltage value, a superconducting heat switch can short-circuit the sensor: the spurious voltage due to the connecting $\mathrm{Cu}$ leads to the room temperature electronics is then measured. The resulting value is subtracted from the voltage measurement when the short circuit is turned to the normal state. Preliminary measurements calibrate the thermocouple: a value of $30 \mu \mathrm{V} / \mathrm{K}$ is obtained. In 
the experiment the flowmeter is operated in a constant temperature difference mode. Typical values of $10 \mathrm{mK}$ are obtained across the flowmeter for a flow rate varying from $1 \mathrm{~g} / \mathrm{s}$ up to $300 \mathrm{~g} / \mathrm{s}$ : for this we have to apply a heater power ranging from 0.1 to $30 \mathrm{~W}$. These measurements were compared with a differential pressure measurement across the nozzle and to a Pitot tube placed $2.5 \mathrm{~cm}$ downstream the anemometers: independently from their own uncertainty these two techniques need to introduce specific approximations (for example the nozzle velocity is obtained from an ad hoc relation with the Pitot tube measured velocity). Good agreement is obtained between the three measuring techniques and we mainly used the flowmeter one. It should be noted that this is the first cryogenic flowmeter, to our knowledge, to measure the mainstream flow from $1 \mathrm{~g} / \mathrm{s}$ up to at least $300 \mathrm{~g} / \mathrm{s}$. This broad measurement range is larger than the ones of commercial flowmeters.

\section{The anemometers}

In turbulence the measurement of the spatial velocity fluctuations $\left(\delta v_{r}=v_{x+r}-v_{x}\right.$, where $v_{x}$ is the velocity at point $x$ ) is the first step to analyse how the energy cascades: it gives access to the flow structures at scale $r$. Such measurements need two detectors at point $x$ and $x+r$. Practically hydrodynamicians use the so-called "frozen turbulence hypothesis" to measure the velocity at a single point versus time: it lies on the hypothesis that the vortex structure turn over time is large compared to the time for this structure to go through the sensor. Then $\delta v_{r}=v(x, t-\tau)-v(x, t)$ with $\tau=$ $r /\langle v\rangle$.

Superconductor anemometers were developed in Grenoble 10 years ago [6]. In the following we describe the anemometers used for this experiment. On Fig. 2, we present the $\mathrm{Pb}-\mathrm{In}$ sensor. Located on a $1 \mathrm{~cm}$ stainless steel frame $(\phi \sim 1$ $\mathrm{mm})$ supporting the $\mathrm{Cu}$ connecting wires $(\phi=150$ $\mu \mathrm{m}, 2 \mathrm{~mm}$ apart), this frame does not perturb the flow. Two silver arms $(\phi=50 \mu \mathrm{m})$ support the detector itself, a $\phi=5 \mu \mathrm{m}$ glass fiber [7]. The carefully cleaned fiber is then glued with silver paint: the free part of the glass fiber is about $1 \mathrm{~mm}$.

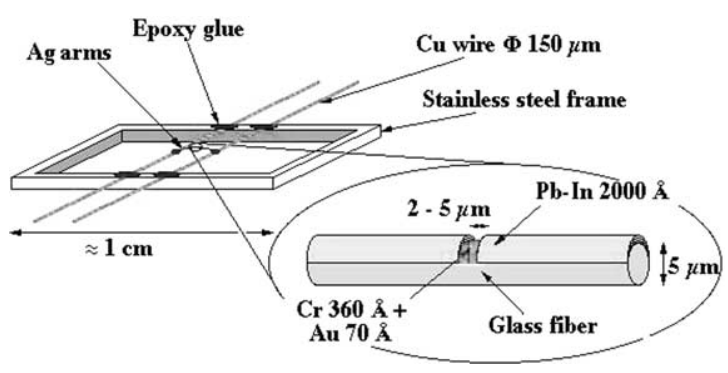

Fig. 2. The superconducting anemometer.

In the next step, a $\mathrm{Cr}$ resistive layer $(360 \AA$ thickness) is evaporated and covered by an oxidation protection Au layer (70 ̊). Another glass fiber with the same diameter is placed perpendicularly to the main one during the last deposition of a superconducting $\mathrm{Pb}-\mathrm{In}$ layer $(2000 \mathrm{~A}, 35 \%$ atomic In, $T_{\mathrm{c}} \approx 7 \mathrm{~K}$ ). The masking glass wire is then removed and the sensor is kept protected from oxidation and humidity under vacuum. Just before the experiment cooling down the detectors are connected in final position.

\section{The measurements}

A specific electronics has been developed. The principle is to heat the bare $\mathrm{Cr}$ spot at a high enough temperature to turn the adjacent $\mathrm{Pb}$-In into the normal state on a given length, corresponding to a given resistance for the whole sensor. This resistance is maintained constant through an acmodulated amplitude current at $10 \mathrm{MHz}$. The output signal is amplified and lock in detected. If the velocity of the flow increases (decreases) the stronger (lower) cooling of the wire is compensated by a larger (lower) amplitude of the heating current: the current variations then reflect the velocity fluctuations. This low temperature sensor is broad band, from dc up to $\approx 1 \mathrm{MHz}$.

The data acquisition system consists of an HP1430E analog digital converter with 18 effective bits. Continuous data blocks of $512 \mathrm{Mpts}$ are written in real time on a hard disk. Such a big data acquisition and storage system is needed to record large data samples, for further statistical analysis of the data. 


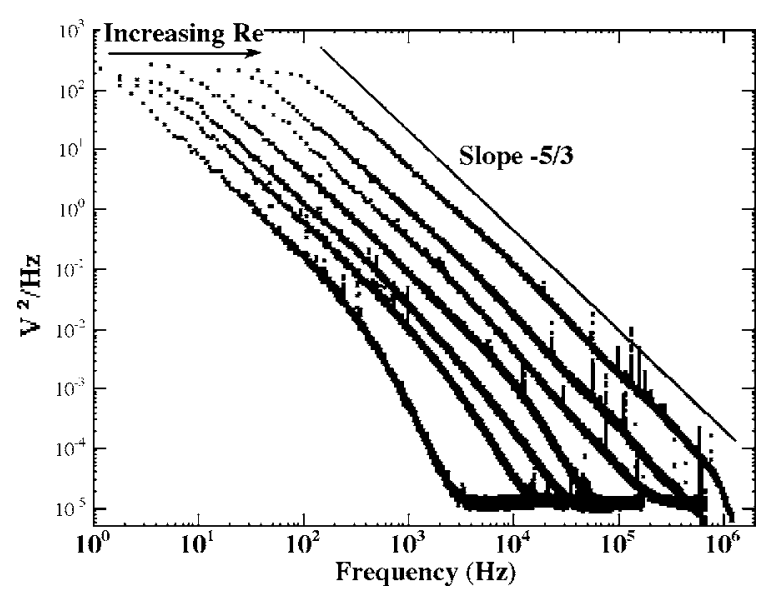

Fig. 3. Voltage FFT for $R e / 10^{6}=0.76,1.25,2.56,3,5,7.7,10$ from left to right. The line with slope $-5 / 3$ on the right is a guide for the eyes (see text).

FFT of the raw voltage data are shown on Fig. 3 for seven different flow rates (the straight line on the right is a guide for the eyes with a $-5 / 3$ slope). Several features can be noted:

(a) The signal dynamics is very large: the measurements expand on seven orders of magnitude on the $y$-axis.

(b) The curves present a plateau on the left with a low threshold, characteristic of the energy injection in the flow, followed by a $-5 / 3$ slope process as predicted by Kolmogorov in the energy cascade process [2]. Finally a steeper decrease, due to the approach of the viscous dissipation limit, is observed for the highest frequencies before to reach a flat zone corresponding to the noise of the measuring system.

(c) The inertial zone between the low threshold and the viscous process becomes wider with $R e$. For the highest $\operatorname{Re}\left(\operatorname{Re}=10^{7}\right)$ it spreads over four orders of magnitude.

(d) The fourth curve $\left(\operatorname{Re}=3 \times 10^{6}\right)$ has been recorded in a previous run with another sensor. This may explain a most accurate measurement of the viscous dissipation zone.

(e) Some spurious peaks are observed at high frequencies. They are not clearly identified but are probably of electric origin.

\section{The data analysis}

After converting the voltage data into velocity data and getting rid of spurious frequencies by empirical mode decomposition [8,9], two analysis have initially been developed. As seen on Fig. 4, the power spectra obtained at $R e=7.6 \times 10^{5}$ and $R e=10^{7}$ superimpose with former experiments [10] in more than 15 flow configurations. This illustrates the universality of the Kolmogorov cascade along the inertial zone, from $L$ down to $\eta$. At $R e=10^{7}$, the inertial zone is the largest ever measured (about one decade larger).

The second data analysis is shown on Fig. 5 as the histogram of the velocity fluctuations:

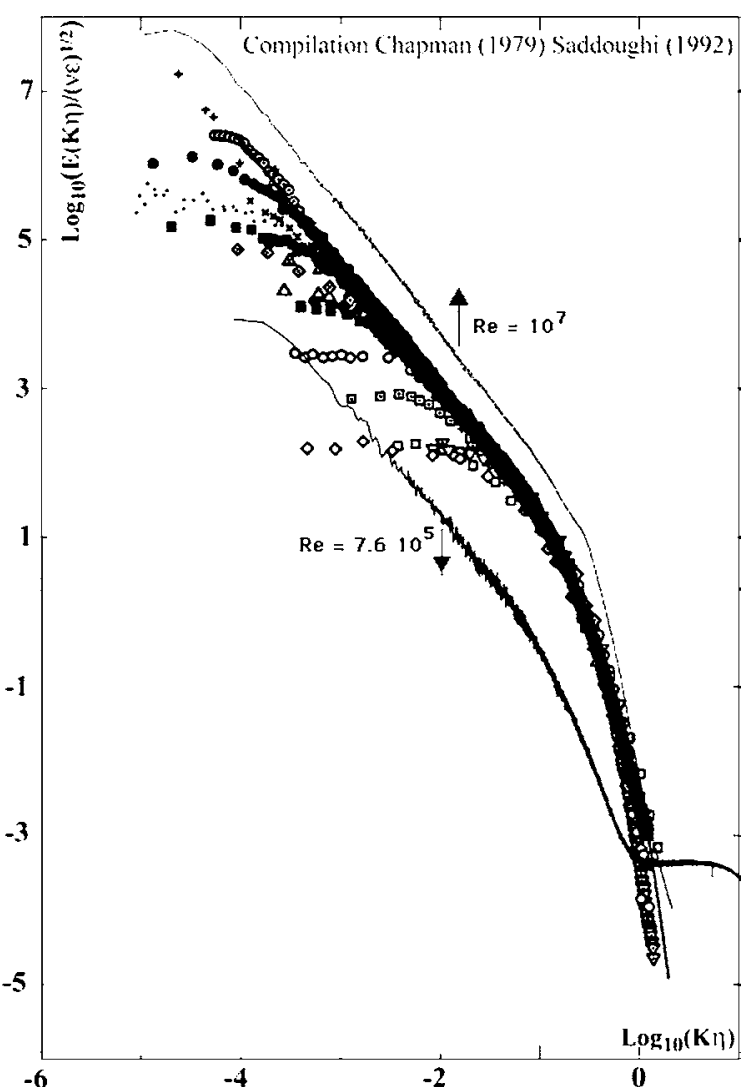

Fig. 4. Measured velocity density spectra for two $R e$ in the CERN experiment compared with other data obtained in grid, boundary layer, pipe, round jet, etc. turbulence experiments (see Ref. [10]). These two spectra have been shifted for clarity down $\left(R e=7.6 \times 10^{5}\right)$ and up $\left(R e=10^{7}\right)$ from the spectra in Ref. [10]. 


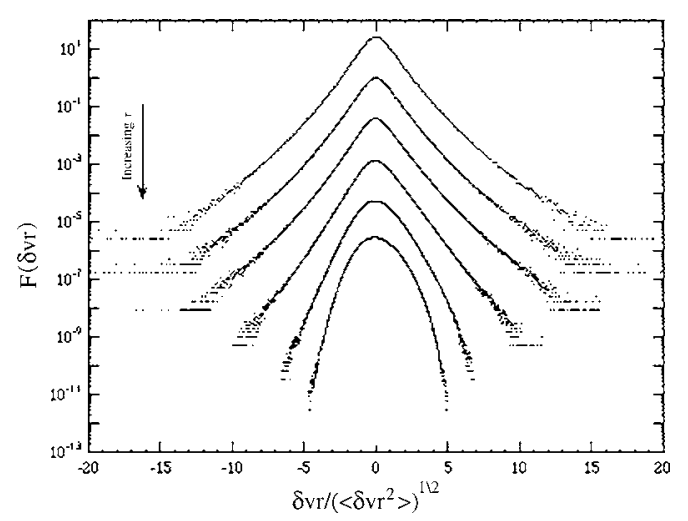

Fig. 5. Velocity increments histograms at $R e=10^{7}$; from top to bottom: $r=7,21,98 \mu \mathrm{m}, 1,12,93 \mathrm{~mm}$. Each histogram has been shifted down for clarity purpose.

$\delta v_{r}(x)=v(x+r)-v(x)$ for $R e=10^{7}$. On this plot the gaussian (parabolic) shape at large $r$ evolves to an intermittent (exponential-like tails) shape for low $r$ values, approaching the dissipation scales. This peaking effect at small $\delta v_{r}$ and the tails increase at large $\delta v_{r}$, characterize the intermittency of the turbulent flow: quiet periods and very active (turbulent) ones are present in the flow.

\section{Conclusion and perspectives}

We have developed a specific superconducting instrumentation giving access to the largest turbulent flow in controlled conditions. We are now analysing the large amount of recorded data to investigate the cascade process at large $R e$. These results will also be compared with simultaneous acoustic measurements, not described in this paper, giving access to the flow vorticity.

From an instrumentation point of view, the flowmeter we present seems well adapted to very large flow rates used in large cryogenic accelerators. For the superconducting anemometer, smaller sensors are needed in order to investigate the viscous dissipative scale. New manufacturing using microfabrication techniques should give access to these ultimate scales.

\section{Acknowledgements}

The investment of CERN cryogenic staff was essential for this experiment. J.L. Bret, G. Garde and C. Guttin from CRTBT were also of a highly valuable help in the development of this superconducting instrumentation. The financial support of the Région Rhône-Alpes through the Emergence Program (no. 99809026 and 99809027), of the French Ministère des Affaires Etrangères through the Embassy in Beijing and of the CNRS are also gratefully acknowledged.

\section{References}

[1] L.F. Richardson, Proc. R. Soc. A 97 (1922) 354.

[2] A.N. Kolmogorov, C.R. Acad. Sci. USSR 32 (1941) 16.

[3] B. Chabaud, Etude de la turbulence dans un jet d'hélium gazeux à basse température, Ph.D. Thesis, Université Joseph Fourier, Grenoble, 1992.

[4] O. Chanal, B. Chabaud, B. Castaing, B. Hébral, Eur. Phys. J. B 17 (2000) 309.

[5] A. Naert, Turbulence dans un jet d'hélium gazeux à basse température, Ph.D. Thesis, Université Joseph Fourier, Grenoble, 1995.

[6] B. Castaing, B. Chabaud, B. Hébral, Rev. Sci. Inst. 63 (1992) 4167.

[7] Vetrotex-Saint Gobain, 767 Quai des Allobroges, 73009 Chambéry, France.

[8] S. Pietropinto, Expérience Grands Reynolds Cryogéniques: GReC, Ph.D. Thesis, Université Joseph Fourier, Grenoble, France, 2002.

[9] N.E. Huang, Z. Sheng, S.R. Long, M.C. Wu, H.H. Shih, Q. Zheng, N.C. Yen, C.C. Tung, H.H. Liu, Proc. Math. Phys. Eng. Sci. 454 (1998) 903.

[10] S.G. Saddoughi, S.V. Veeravalli, J. Fluid Mech. 268 (1994) 333. 